\title{
Overweight and Obese College Students' Perceived Barriers and Motivators for a Healthy Lifestyle
}

\author{
Yoonsin Oh, PhD \\ Department of Kinesiology, \\ University of Wisconsin-Eau Claire, Eau Claire, WI, USA \\ Boung Jin Kang, PhD \\ Department of Education, Psychology, \& Health, \\ Elizabeth City State University, Elizabeth City, NC, USA \\ Soojin Yoo, PhD \\ Department of Health \& Human Performance, \\ University of Texas, Rio Grande Valley, Edinburg, TX, USA

\section{Angelica Lopez} \\ Department of Allied Health Sciences, Southwestern Oklahoma State \\ University, Caddo Kiowa Technology Center, Fort Cobb, OK, USA
}

\section{doi: 10.19044/ejes.v3no4a17 URL:http://dx.doi.org/10.19044/ejes.v3no4a17}

\begin{abstract}
This qualitative study explored overweight and obese college students' experiences of obesity. Overweight and obese university students (BMI 25 or higher) from a southwestern regional university in the United States were recruited for in-depth qualitative interviews. Interviews were conducted face-to-face in a private room during the academic year 2013-14. A team of trained qualitative researchers used conversational interviews to discuss the students' experiences for 45-60 minutes. Interviews were audiorecorded and transcribed. Data analysis used qualitative emergent themes and categorization. Researchers analyzed the data at team meetings for triangulation and validation. Nineteen overweight or obese university students (female $=11$ and male=8) participated in the study. Sixty-three percent (12 out of 19) were obese and the remainder were overweight. Seventy-three percent (14 out of 19) did not meet the physical activity guidelines for Americans. Time and motivation were barriers for physical activity. Seventy-three percent (14 out of 19) reported eating unhealthy foods. Lack of time and convenience were barriers to eating healthier. They showed a lack of knowledge on how to make healthy food choices. Eleven out of nineteen (57\%) participants were self-conscious about their body, and half were having trouble finding clothes that fit. These results support the previous literature on psychological issues, lack of daily physical activity,
\end{abstract}


and lack of a healthy diet. This suggests that health promotion is needed for college students to foster healthier lifestyles.

Keywords: Overweight, Barrier, Motivator, Physical Activity, Nutrition

\section{Introduction}

Obesity is a worldwide health problem that has continuously increased in the last 33 years (Ogden et al., 2006). According to the Center for Disease Control, 69\% of Americans age 20 or older are overweight or obese (Ogden et al., 2014). In previous research, about two-thirds (66\%) of college students surveyed at a southwestern regional university were also overweight or obese (Oh, Boss, \& Lopez, 2014). Overweight and obese adults have negative experiences including discrimination, bullying, teasing, and social isolation (Thomas et al., 2007). This causes self-consciousness and body dissatisfaction (Sarwer, Thompson, \& Cash, 2005).

Research has shown that the majority of overweight or obese people have already experienced some type of negative experience in their childhood that usually continues through adulthood causing psychological issues: self-consciousness, attitude, and body dissatisfaction (Thomas et al., 2008). Based on a survey study published in Psychology Today, half of males and two-thirds of females have reported to be dissatisfied with their bodies and body weight; the majority of females said they were mostly dissatisfied with their abdomen, thighs, and hips (Sarwer, Thompson, \& Cash, 2005).

Entering college is a key transitional period for young adults. They face challenges adjusting to new surroundings and workloads (Greaney et al., 2009). College students appear to be even more prone to weight gain than those who do not attend college (LaCaille et al., 2011). College enrollment is a documented time for weight gain, averaging 3 to 7 pounds in the first year (Delinsky \& Wilson, 2008). Approximately 95\% of students report eating sweets and fats, and only 6\% eat two or more servings of fruits or vegetables daily (Brunt et al., 2008). Furthermore, a sedentary lifestyle compounds the problem with $50 \%$ of college students not meeting their required daily physical activity (Keating et al., 2005). This qualitative study explored American overweight and obese college students' personal stories about their experiences of obesity focusing on their behaviors and perception including physical activity, diet, and their perceived motivators and barriers for healthy behaviors. 


\section{Methodology: \\ Recruitment}

Overweight and obese university students (Body Mass Index 25 or higher) from a southwestern regional university in the United States were recruited for in-depth qualitative interviews. Participants were recruited via flyers on campus, on the University department website, and by e-mail. Interested participants contacted the researchers, and the participants were given a brief description of the study and a consent form a week prior to the interview to decide their participation. Following the consent process, an initial screening took place to qualify participants for the study. Each participant's height, weight, and body fat percentage were measured by a researcher. A SECA portable stadiometer was used for the height measurement. A TANITA BF-350 body composition analyzer was used for weight and body fat percentage measurements. The qualified participants filled out a basic demographic survey including sex, age, birth date, ethnicity, geographical location, marital status, number of children and adults living in their household, and current household income.

\section{Data collection}

Data were collected using semistructured interviews by researchers trained in qualitative techniques. Interviews were conducted face-to-face in a private room with one or two researchers during the academic year 20132014. The researchers used conversational interviews to discuss the participants' experiences for 45-60 minutes. The researchers asked participants about their daily college life routines including physical activity, diet habits, barriers, challenges of being overweight or obese, and motivators to become healthier. Each interviewer asked a series of key questions including the following:

1. Can you describe your daily physical activities?

2. What are the barriers for you to become physically active?

3. What would motivate you to become physically active?

4. Can you tell me what you eat in general from breakfast to dinner including snacks?

5. What are the barriers for you to eating healthier?

6. What would motivate you to eat healthier?

Interviews were audio-recorded and transcribed by trained researchers. Each answer was organized in an Excel spreadsheet by interview question number.

\section{Data analysis}

Data analysis used qualitative emergent themes and categorization based on grounded theory (Glaser \& Strauss, 1967). The researchers used 
open coding to categorize the major ideas from the interview answers using triangulation for validation.

\section{Results:}

\section{General Characteristics}

Nineteen overweight or obese university students (female $=11$ and male=8) participated in the study (see Table 1 for general characteristics). The average age of participants was 30 years (range 19-53) and less than half (9; 47.4\%) had never been married. Participants had a mean BMI of 31.8, and more than half $(12 ; 63.2 \%)$ were obese. Based on the TANITA body composition analyzer data, a majority of participants $(16 ; 84 \%)$ had high and very high body fat percentages for their sex and age.

All participants had tried to lose weight in the past. Approximately half $(11 ; 57 \%)$ had tried to lose weight by only controlling their diet. Participants reported that they had tried diets such as counting calories, fasting, diet pills and diet programs such as Weight Watchers, NutriSystem the Atkins diet. A little more than a quarter (5; 26\%) tried to lose weight by only exercising. Participants reported that they used aerobic activities including using a treadmill, video tape workouts, and steppers. Only two participants (10\%) tried to lose weight using both diet and exercise.

Table 1.

Participant characteristics

\begin{tabular}{ll}
\hline \multicolumn{1}{l}{ Characteristic } \\
\hline \multicolumn{1}{l}{ Age } & $19-53$ \\
\hline \multicolumn{1}{l}{ Range } & 30 \\
\hline Sex & $11(57.9 \%)$ \\
\hline Female & $8(42.1 \%)$ \\
\hline Male & \\
\hline Marital Status & $9(47.4 \%)$ \\
\hline Single & $4(21.1 \%)$ \\
\hline Married & $5(26.3 \%)$ \\
\hline Divorced & $1(5.3 \%)$ \\
\hline Separated & \\
\hline Geographical location & $10(52.6 \%)$ \\
\hline Urban & $2(10.5 \%)$ \\
\hline Suburban & $7(36.8 \%)$ \\
\hline Rural & \\
\hline Obesity Classification & $7(36.8 \%)$ \\
\hline Body Mass Index & $12(63.2 \%)$ \\
\hline Overweight & $6(31.6 \%)$ \\
\hline Obese & $6(31.6 \%)$ \\
\hline Obese I & \\
\hline Obese II & $3(15.79 \%)$ \\
\hline Body Fat Percentage & $3(15.79 \%)$ \\
\hline Moderate & $13(68.42 \%)$ \\
\hline High & \\
\hline Very High & \\
\hline
\end{tabular}




\section{Daily physical activity and perceived barriers}

The researchers asked "Can you describe your daily physical activities?” Based on their report, seventy-three percent (14 out of 19) did not meet the physical activity guidelines for Americans (150 minutes of moderate intensity aerobic activities; U.S. Department of Health and Human Services, 2008). Participant reasons fell into four categories: a lack of time (31\%), feeling tired (26\%), lack of internal motivation (26\%), and selfconsciousness (17\%). The most frequently reported barrier was time: "Time, having yeah, trying to schedule it in with all of the commitments I have" (50 year old female). Feeling tired was a barrier for participants as well. Participants reported not having the endurance they needed to be physically active: "I don't have the endurance I once had. I get tired easily" (25 year old male). Lack of internal motivation was also a challenge for participants, $26.3 \%$ of the students reported not having the motivation to be physically active. "I tried working out a few times but I'm really not a physically active person so I give up because I'm too lazy" (21 year old female).

Participants also recognized their lack of internal motivation and body image as a barrier: "Um, one thing is laziness... and I think that's the main thing laziness and not wanting to work out when other people are around the gym." (20 year old female). The participants showed a common theme of self-consciousness and an uncomfortable feeling either working out or eating in front of other people.

\section{Perceived motivators for physical activity}

Participants reported their perceived physical activity motivators as seeing quick results (physical appearance), realization of additional weight gain, and social support. Half of the interviewees (11; 57\%) mentioned that seeing results in terms of losing weight, developing a better physical appearance, and/or becoming physically stronger would motivate them. "I wanna see it immediately, I wanna see, if you say I do this weight loss program and I can lose 10 pounds in a week then that's what I wanna do" (37 year old female). Another common theme we observed was that the realization that gaining additional weight would cause health threats (e.g., their medical doctor recommended losing weight) was motivating. "If I gain more weight, ya, well, I mean if I got up to 260 pounds to 280 pounds I would definitely change something" (33 year old male). Having a workout partner was also motivating to become more physically active. "A workout partner. Not like a trainer but like a good friend would help. I do a lot better with someone with me" (25 year old male).

The researchers noticed that there were three participants who could not think about what would motivate them to be physically active. "Um, that's tough question. What would motivate me?...Um...honestly I have no 
clue. I think I've tried, I've got pictures of what I've wanted to look like and I've tried a lot of variations, I've tried telling myself, looking at myself in the mirror telling myself get up and I always slack off. ...um......I don't know maybe laziness; I don't feel like getting up and going to the gym" (20 year old male).

\section{Daily eating and perceived barriers}

Seventy-three percent (14 out of 19) reported eating unhealthy foods throughout the day. The unhealthy foods that participants reported were highly processed foods containing high sodium such as fast food, microwavable dinners, canned food, and boxed food. Forty-two percent (8 out of 19) showed a lack of knowledge on how to make healthy food choices. "Um probably just to know what to pick out when I go to the grocery store... but knowing what is good and what is not anymore is the thing. Umm, they [the school] could offer maybe some kind of nutrition class that would help me decide what's actually good for me and what's not" (44 year old male).

A participant reported eating in his car by himself because of being self-conscious about binge eating. "The last time I went I got a 20-piece chicken mcnuggets, 2 mcdoubles and a medium french fry, but that's not usual, that's kind of more of a if I were to workout really hard one day, then I'll eat something like that to make sure I'm eating" (22 year old male).

Participants were asked if there were any barriers and challenges that they faced when trying to eat healthily. Their perceived barriers for eating healthy foods were lack of time, inconvenience, money, a lack of social support, and temptation or addiction to foods. Thirty-six percent of interviewees (7 out of 19) reported that time and inconvenience was a barrier for healthy eating: "Having the time to eat healthier umm being that I have my kids and a thousand other things going on, it is kind of hard for me to sit there and make something healthy instead of just grabbing something and going" (29 year old female). Twenty-six percent (5 out of 19) stated that money was a factor when trying to eat healthily. Participants perceived that buying healthy food is more expensive than buying unhealthy food: "Money to eat healthy, because cost of living is high, the cheap stuff isn't healthy for you" (21 year old female).

Lack of social support was also a challenge in eating healthier: " $A$ lot of it, my family is southern so of course a lot of it is fried foods. That's been my hardest part of losing weight is at home. I'll try to buy healthy foods but of course on the weekends we will visit my parents and its always southern cooking" (25 year old male). Foods like desserts and cheeses were mentioned as temptations: "Yes, just choice I guess. It's hard to resist temptations like dessert. If I didn't buy it, I wouldn't eat it but I do buy it and 
I do eat it. It's hard for me not to enjoy the little things; I don't see myself as overweight so I can eat dessert" (19 year old male).

\section{Perceived motivator for healthy eating}

Participants were asked what would motivate them to eat healthier. Their perceived motivators to eat healthy foods fell into four categories: health concerns, self motivation, \& inexpensive healthy food availability. Six out of nineteen participants (32\%) reported that having health problems would motivate them to eat better: "I'm already scared of heart disease and stuff like that the motivations are there for me, like trying to eat healthier. Like I don't want to end up like my mom, I don't want to have chest pain and have to keep natural glycerin in my pocket all the time or anything like that I don't wanna have a stroke like my brother did and he actually my ex-step brother past away last year and he was only a few years older than me and he passed away of a stroke already. But I mean he had other health problems too but things like that scare me into being motivated basically" (29 year old female).

Self-motivation was a motivator for forty-two percent (8 out of 19) of participants: "It's gonna have to be me" (47 year old male). The other common motivator discussed was the availability of inexpensive healthy food: " $m$... cheap prices (laughing) would make it a lot easier to be willing to do that or be able to do that. Mainly all boils out to money and time, cause I prefer to eat healthy cause I feel better when I do but it just again time and money" (21 year old male).

\section{Self-consciousness}

Self-consciousness was an emergent theme that arose in the course of the interviews. Eleven out of nineteen (57\%) participants responded that they are self-conscious about their body: "It makes you not take pictures of your whole body. Ever. You only take head shots. It makes you feel inadequate next to a skinny person, so you're kind of less likely to talk to somebody new" (29 year old female). Half (11; 57\%) of the interviewees were having trouble finding clothes that fit: "It makes it hard to find clothes that actually fit, and then you feel self-conscious in clothes that do fit cause sometimes they're too tight in certain areas" (21 year old female). These were not exclusive: one interviewee delayed enrolling in a required physical education course at the University until she had to for her graduation requirements: "I waited three years going here before I even took a PE class cause I was so scared to even get in front of somebody in athletic clothes" (29 year old female).

These issues also affected participant eating behaviors as well. One participant described eating by himself in his car because he did not want to 
show what or how much he eats in front of others: "I am not eating on campus. I'm self-conscious probably is really why honestly if that makes any sense. I don't like eating in front of people" (22 year old male).

\section{Conclusion:}

The purpose of this qualitative study was to gain perspectives from overweight and obese college students on their past and present experiences including weight loss attempts, physical activity, eating habits, and their perceived barriers and motivators for healthy behaviors. Due to the nature of this study, there are several limitations. Because participation in this study was voluntary, there may be a self-selection bias within the sample. It should be noted that during our interview process, the researchers did not define healthy or unhealthy eating but instead had participants provide their own definition.

From the results, there were shared commonalities between overweight and obese college participant's perception toward physical activity and eating behaviors. Lack of knowledge was the most prevalent barrier for the participants. They were unable to identify healthy and unhealthy behaviors that aligned with national guidelines and recommendations. The overweight or obese participants in this study had unpleasant feelings about themselves, which affected their physical, emotional and social health. Self-consciousness was another key barrier for participants, along with motivation, and negative personal experiences. The results support the previous literature on psychological issues (Sarwer, Thompson, \& Cash, 2005), the lack of daily physical activity (Keating et al., 2005), and the lack of healthy diets (Brunt et al., 2008). This suggests that health promotion is needed for overweight or obese college students to foster healthy lifestyles.

In addition, we wanted to suggest possible actions that the university could take to help those students. The study showed that participants were lacking in knowledge and motivation to make healthy lifestyle choices. Students wanted nutrition classes that provided information and guidelines on what to eat and how to cook healthily. While the university offered nutrition classes, student participants either were unaware of them or did not acquire functional knowledge from them. Similar to Greaney et al.'s (2009) research, the participants wanted students, faculty, staff, and administrators to work together to make meaningful changes within the university environment.

We conclude that providing educational opportunities on what to do to be physically active, and how to do it would benefit obese and overweight individuals. They also need to be educated on dieting and weight loss. Participants reported negative past experiences that caused them to become 
overweight and being unhappy with their current weight. We also recommend counseling programs to help them overcome their past negative experiences that were related to their physical and mental health. Further research should include study a younger population as well.

\section{References:}

Brunt, A., Rhee, Y., \& Zhong, L. (2008). Differences in dietary patterns among college students according to body mass index. Journal of American College Health, 56(6), 629-634.

Delinsky, S. S., \& Wilson, G. T. (2008). Weight gain, dietary restraint, and disordered eating in the freshman year of college. Eating Behaviors, 9 (1), 82-90.

Greaney, M. L., Less, F. D., White, A. A., Dayton, S. F., Riebe, D., Blissmer, B., Shoff, S., Walsh, J. R., Greene, G. W. (2009). College students' barriers and enablers for healthful weight management: A qualitative study. Journal of Nutrition Education and Behavior. 41(4), 281-286.

Keating, X. D., Jianmin, G.,Piñero, J. C,. \& Bridges, D. M. (2005). A metaanalysis of college students' physical activity behaviors. Journal of American College Health, 54 (2), 116-125.

LaCaille, L. J., Dauner, K. N., Krambeer, R. J., \& Pedersen, J. (2011). Psychosocial and environmental determinants of eating behaviors, physical activity, and weight change among college students: A qualitative analysis. Journal of American College Health. 59 (6), 531-538.

Oh,Y., Boss, S., \& Lopez, A. (2014). Body Composition in Health and Physical Education Undergraduate Students. Poster presented at the Oklahoma Research Day, Edmond, OK.

Ogden, C.L., Carroll, M.D., Curtin, L.R., McDowell, M.A., Tabak, C.J., \& Flegal, K.M. (2006). Prevalence of overweight and obesity in the United States, 1999-2004. Journal of the American Medical Association, 295(13):1549-55.

Ogden C. L., Carroll, M. D., Kit, B.K., \& Flegal K. M. (2014). Prevalence of childhood and adult obesity in the United States, 2011-2012. Journal of the American Medical Association, 311(8), 806-814.

Sarwer, D. B., Thompson, J. K., \& Cash, T. F. (2005). Body image and obesity in adulthood. Psychiatric Clinics of North America, 28(1), 69-87.

Glaser, B., \& Strauss, A. (1967). The Discovery of Grounded Theory: Strategies for Qualitative Research. Chicago, IL: Aldine Publishing Company.

Thomas, S. L., Hyde, J., Karunaratne, A., Herbert, D., \& Komesaroff, P. A. (2008). Being 'fat'in today's world: a qualitative study of the lived experiences of people with obesity in Australia. Health Expectations, 11(4), 321-330. 
U.S. Department of Health and Human Services (2008). Physical Activity Guidelines for Americans, Retrieved from http://www.health.gov/paguidelines/pdf/paguide.pdf 